\title{
Cumulative Contextual Risk, Maternal Responsivity, and Social Cognition at 18 Months
}

by

Mark Wade

\begin{abstract}
A thesis submitted in conformity with the requirements
for the degree of Master of Arts in School and Clinical Child Psychology Graduate Department of Applied Psychology and Human Development University of Toronto
\end{abstract}

(C) Copyright by Mark Wade (2012) 


\title{
Cumulative Contextual Risk, Maternal Responsivity, and Social Cognition at 18 Months
}

\author{
Mark Wade \\ Master of Arts \\ Applied Psychology and Human Development \\ University of Toronto
}

2012

\section{Abstract}

By 18 months children demonstrate a range of social-cognitive skills that reflect their emerging capacity to understand and engage in intentional relations with others. Intention understanding is a critical component of children's social cognition at this age. Although individual differences in social cognition have been linked to neurocognitive maturation, socio-cultural models of development suggest that environmental influences operate in the development of intention understanding, with distal factors operating through proximal processes. In the current study of 501 children and their mothers, we tested and found support for a model in which an accumulation of distal environmental risks was associated with lower maternal responsivity, which was in turn associated with lower social-cognitive competency at 18 months. In addition, part of this effect operated through children's concurrent language ability. Findings are discussed with respect to the Vygotskian themes of internalization and semiotic mediation. 


\section{Acknowledgments}

First, I would like to thank my friends and family for their continued support throughout the completion of my research activities. A special thanks to my mother and father for their endless encouragement and longstanding emphasis on following my career aspirations with dedication and enthusiasm. I would also like to thank my colleagues and peers, with whom many memories and experiences were shared, and who made this pursuit truly enjoyable. A particular note of appreciation goes to Heather Prime and Dillon Browne (triumvirate), who were not only instrumental in the advancement of my educational and professional development, but who have become lifelong friends and inspirational figures in my life. Additional thanks goes to Kate Bryant, Zohrah Haqanee, Jessica Taylor, Joyce Mak, Aarti Kumar, Kristen Frampton, JeanChristophe Meunier, and André Plamondon for their specialized expertise and social support throughout the last two years. Finally, I would like to thank my supervisor, Jenny Jenkins, who has made the single most important contribution to my growth as a researcher and professional in the field of child development. Not only has she afforded me the skills to become a proficient scientist, but she has taught me the value of dedicating oneself to an area of importance and exhausting all avenues to effect positive change. 


\section{Table of Contents}

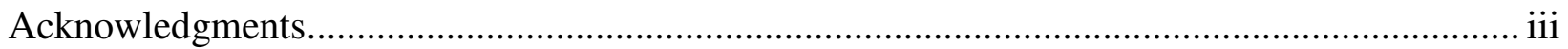

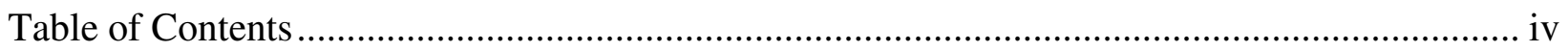

List of Tables …......................................................................................................... vi

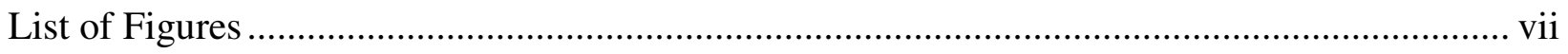

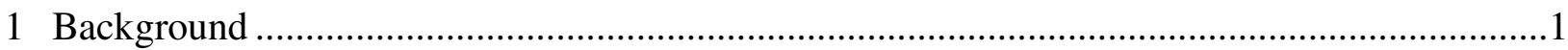

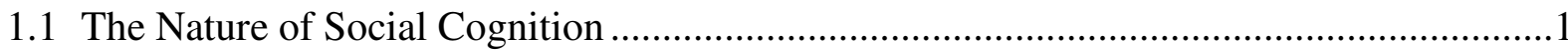

1.2 Social Cognition in Infancy and Childhood..............................................................

1.3 Social-Cognitive Skills and Different Forms of Intention Understanding .......................2

1.4 A Sociocultural Perspective on Social-Cognitive Development ...................................4

1.5 Distal and Proximal Social-Environmental Influences on Social-Cognitive

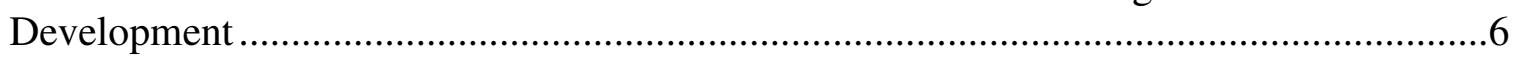

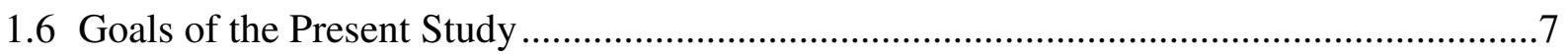

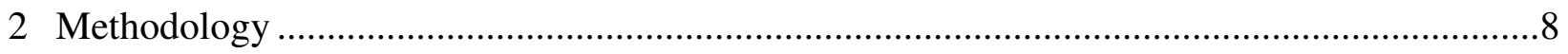

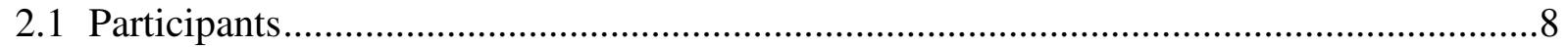

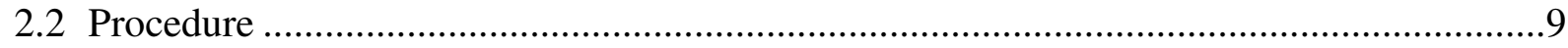

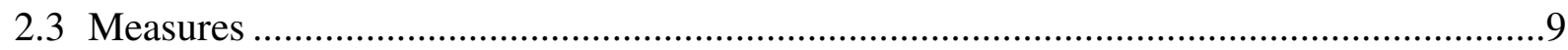

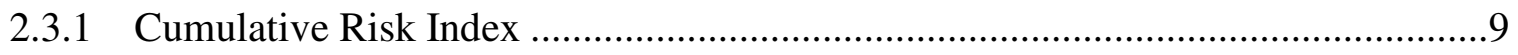

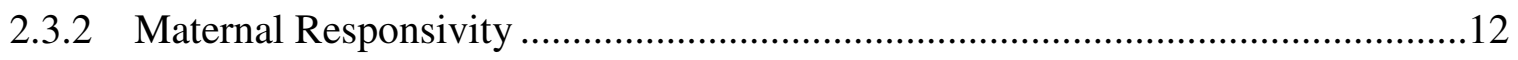

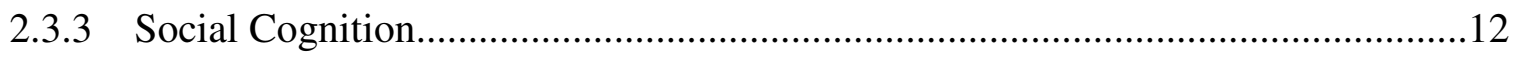

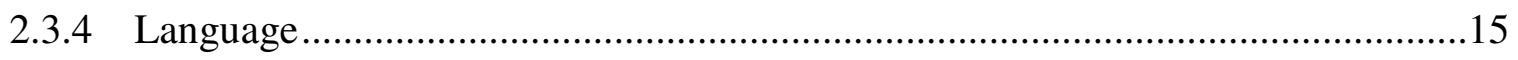

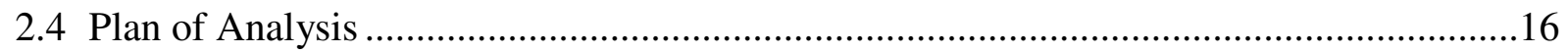

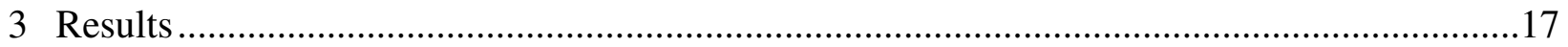

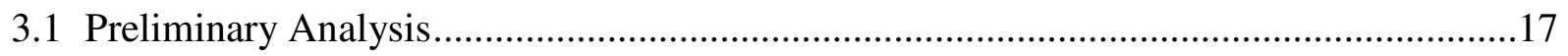

3.2 Testing the Measurement Model for Social Cognition ................................................ 17

3.3 Testing the Proposed Indirect Paths - The Structural Model ........................................20 


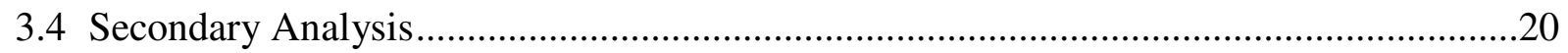

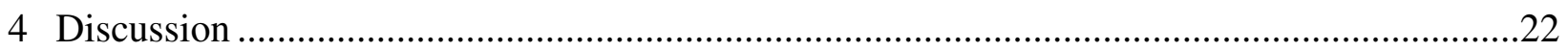

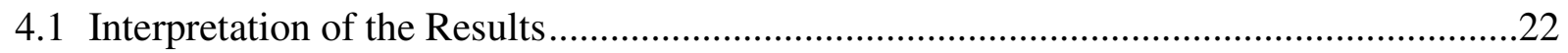

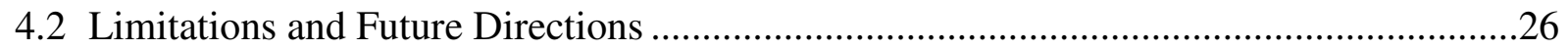

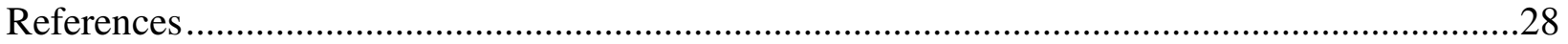




\section{List of Tables}

Table 1. Correlations, mean scores, standard deviations, and number of participants for study

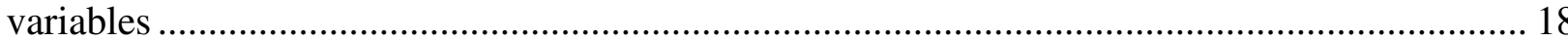




\section{List of Figures}

Figure 1. Measurement model for the social cognition and maternal responsivity latent

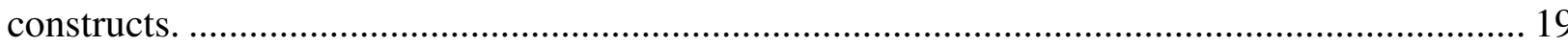

Figure 2. Hypothesized model on the relations between distal cumulative risk, maternal responsivity, child language, and social cognition at 18 months......................................... 21 


\section{Background}

\subsection{The Nature of Social Cognition}

Social cognition is the ability to understand why people behave the way they do. This is accomplished by gaining an awareness of the mental states of oneself and others, including beliefs, desires, intentions, and emotions. The ability to interpret behaviour in terms of psychological states is required for complex social interactions early in life. Indeed, development of social-cognitive skills has consequences for children's psychosocial well-being. For example, preschool children with poor social cognition display heightened conflict and communication problems with friends (Dunn \& Cutting, 1999), lower levels of acceptance among peers (Slaughter, Dennis, \& Pritchard, 2002), less social competence (Astington, 2003), more behaviour problems (Hughes \& Ensor, 2006), and less sophisticated academic skills (Astington $\&$ Pelletier, 2005). Deficits in social awareness have also been linked to pervasive developmental disorders such as autism (e.g. Baron-Cohen, 1989; Baron-Cohen, 1997; Baron-Cohen, Leslie, \& Frith, 1985). Since social cognition is predictive of later adjustment, it is important to understand the development of these early competencies. This process requires at least two pre-conditions: (1) understanding the extent to which different aspects of early social cognition are related to one another; and (2) identifying ecological variables that contribute to social-cognitive functioning. The present thesis aimed to advance these two areas of research.

\subsection{Social Cognition in Infancy and Childhood}

Young children demonstrate their social awareness through various behaviours and social interactions with others. For instance, by about 3 months infants are able to coordinate vocalizations and facial expressions with other people (Reddy, 2008), and by about 9 months they are capable of following and directing the attention of others (Carpenter, Nagell, \& Tomasello, 1998). They are also able to adopt emotional expressions towards objects based on the emotional states of other people (Mumme, Fernald, \& Herrera, 1996). These abilities represent a progression in social understanding that continues to develop over the first few years of life. However, these rudimentary abilities only require that infants coordinate or match their experiences with others, and not necessarily that they distinguish between their own and others' mental or physical states. On the other hand, recent investigations have begun to document the 
possibility that young infants are capable of attributing some mental states to others when ageappropriate response tasks are used (see Baillargeon, Scott, \& He, 2010 for a review).

Regardless of the exact age at which infants begin to ascribe the full range of mental states to other agents, it is clear that by about 18 months children recognize themselves and others as similar yet distinct individuals who may possess different perspectives and orientations to events and objects in the environment (Moore, 2007). It is around this time that children are able to objectively recognize themselves in a mirror (Brownell, Zerwas, \& Ramani, 2007; Nielsen \& Dissanayake, 2004), display empathic and prosocial behaviours (Warneken \& Tomasello, 2006; Zahn-Waxler \& Radke-Yarrow, 1990), and engage in cooperative interactions with others (Warneken, Chen, \& Tomasello, 2006). One fundamental aspect of social cognition at this age is the ability to understand that peoples' actions are driven by purposeful intentions. According to Moore (2007), intentional relations connect actors to objects in the world, and understanding such relations allows children to appreciate that behaviour is goal-directed. Many studies have now shown that by 12 to 18 months children are able to represent a variety of intentional relations (Carpenter, Call, \& Tomasello, 2005; Gergely, Nádasdy, Csibra, \& Bíró, 1995; Wellman, Phillips, Dunphy-Lelii, \& LaLonde, 2004; Woodward, 1998).

Infants' understanding of intentionality may lay the foundation for more mature social understanding that is rooted in social experience. This developmental view of social cognition is consistent with the notion that early intuitive awareness during infancy becomes more explicit and reflective understanding in toddlerhood (San Juan \& Astington, 2012; Thoermer, Sodian, Vuori, Perst, \& Kristen, 2012). However, even at 18 months infants' ability to understand others as unique psychological beings (and intentional agents) requires two complementary processes: first, children must understand that others have subjective experiences of the world that may be different from their own; and second, they realize that they themselves are an objective entity (Barresi \& Moore, 1996; Moore, 2007). These central elements of intention understanding are captured in a range of social-cognitive behaviours that emerge in the second year of life.

\subsection{Social-Cognitive Skills and Different Forms of Intention Understanding}

There are different types of intentional relations, and it is useful to describe them according to the social-cognitive behaviours that children demonstrate at 18 months. According to Moore 
(2007), some intentional relations are epistemic, which refers to cognitive or knowledge-based forms of intention understanding. This kind of understanding supports infants' ability to engage in joint attention. Although infants can use their own gaze and gestures to direct the attention of others beginning at about 9 months, their capacity to coordinate intentional relations with others in order to engage in a shared social activity is not fully established until 15 to 18 months (Tomasello \& Carpenter, 2007; Tomasello, Carpenter, Call, Behne, \& Moll, 2005) A second type of intentional relations is affective or emotional. A significant benchmark in understanding the independent emotional orientations of oneself and others at 18 months is empathic responding. According to Zahn-Waxler and Radke-Yarrow (1990), empathy refers to an individual's ability to experience others' affective and/or psychological states. Zahn-Waxler, Radke-Yarrow, Wagner, and Chapman (1992) have provided evidence that children's prosocial behaviour is associated not only with empathic concern for the distress of others, but also with attempts to label and understand another's distress by making appropriate comments or asking insightful questions. Finally, conative intentional relations relate to purposeful action, including desires and acts of volition. An example includes cooperative behaviours, wherein individuals take on different roles but work towards a shared goal. Brownell and Carriger (1990) tested children aged 12, 18, 24, and 30 months on joint problem solving tasks in which one child operated a spring-loaded handle that released toy animals to the other child, who needed to position themselves appropriately to catch the animals. The tasks required spatial and temporal coordination of actions, and could not be successfully completed by either child alone. Results showed that no 12-month-olds evinced cooperative behaviours, whereas the greatest improvements were apparent between 18 and 24 months. Warneken, Chen, and Tomasello (2006) extended these findings by showing that 18-month-olds also attempt to re-engage an adult confederate who has ceased cooperative behaviour in an effort to restore shared intentionality. Thus, intention understanding supports children's engagement in a range of social-cognitive behaviours in the second year of life.

Also emergent around 18 months is the ability of children to represent themselves as objective agents - individuals who are acting on the world, not simply experiencing first-person perspectives (Nielsen \& Dissanayake, 2004). Recognizing oneself as an objective entity means that children conceive of themselves as the target of others' intentional relations, evidenced by the simultaneous emergence of the social emotions - embarrassment, guilt, shame, pride (Lewis, 
Sullivan, Stanger, \& Weiss, 1989). Experiencing these emotions requires the child to understand that they can be judged by others, thus illustrating their awareness of the objective self.

In sum, social cognition at 18 months can be described in terms of children's ability to understand and engage in intentionality with others - a capacity that relies on an awareness of the objectivity of oneself and the independent experiences of others. Joint attention, empathy, cooperation, and self-recognition are skills that index these fundamental aspects of social cognition at this stage of development.

\subsection{A Sociocultural Perspective on Social-Cognitive Development}

Social cognition across childhood has been linked to numerous biopsychosocial factors. For example, social cognition (including 'theory of mind') develops in several distinct stages which can be mapped onto advancements in neurocognitive functioning, including the orbito-frontal cortex (Stone, Baron-Cohen, \& Knight, 1998), anterior cingulate cortex (Vogeley, et al., 2001), temporal-parietal cortex, and the amygdala (Siegal \& Varley, 2002). Various regions of the prefrontal cortex have also been implicated in theory of mind development (Spreng, Mar, \& Kim, 2009). In addition to these maturational changes, behavioural genetics studies have shown that a large portion of the variability in theory of mind performance at age 5 is attributable to shared environmental factors (Hughes, et al., 2005). Some 'hybrid' models of social-cognitive development hold that innate mechanisms may guide the development of early social-cognitive competencies, whereas environmental influences may become more pertinent as children's social horizons are broadened throughout life (Meltzoff, Gopnik, \& Repacholi, 1999). Despite these findings, there is a surprising paucity of literature examining how social-environmental factors contribute to children's social cognition early in development (i.e. before the preschool period).

One of the central tenets of Vygotskian (1997) theory is that mental functioning represents an internalization of interpersonal experience. A logical extension of this work is that children's understanding of others' minds is rooted in social interaction (see Fernyhough, 2008). The earliest and most important of these interactions are those that occur with caregivers. Bowlby referred to the goal-corrected partnership in which a caregiver and their child are able to represent and respond to the internal states of each person in the dyad. Two components of social interaction seem critical for the development of social cognition. There is an affective component 
to parenting, operationalized by concepts such as engagement, attunement, contingency, reciprocity, and sensitivity. These elements of parenting have been found to predict different aspects of social cognition in the preschool period (Ereky-Stevens, 2008; Hughes, DeaterDeckard, \& Cutting, 1999; Meins, Fernyhough, Russell, \& Clark-Carter, 1998; Symons \& Clark, 2000). This might be seen as the 'motivational' aspect of the goal-corrected partnership: there is reward for the child in social interaction. The other component can be referred to as cognitive challenge, and refers to parental behaviours that supply children with the cognitive tools (including discourse) that are required for representing their own and others' internal states. These include parental behaviours such as talk about the mind (Laranjo, Bernier, Meins, \& Carlson, 2010; Ruffman, Slade, Devitt, \& Crowe, 2006; Taumoepeau \& Ruffman, 2006), reflection (Fonagy, Steele, Steele, Moran, \& Higgitt, 1991), mind-mindedness (Meins, et al., 2002), and autonomy support (Bernier, Carlson, \& Whipple, 2010). Thus, the affective component of parenting gets children motivated to engage with others and provides opportunities for cognitive challenge which, accordingly, affords children the alternative perspectives and orientations that are needed to learn about others' minds (Fernyhough, 2008). In this regard, it is a combination of both affective and cognitively stimulating parenting behaviours that would be needed to foster children's early social cognition.

Language skills are believed to mediate or enhance the development of other cognitive processes, such as the ability to represent and reason about others' internal experiences (Fernyhough, 2008). From this perspective, cultural influences on social understanding can be conceived of as specific patterns of social interactions and culturally-derived semiotic systems (e.g., language) that are essential to social-cognitive development. These views corroborate those of Nelson (2005), who emphasized how emergent language faculties contribute to children's capacity to construct mental representations. However, other accounts of environmental influences on social-cognitive development do not feature language as a central mediator of social understanding, instead arguing that early forms of social cognition (i.e., intention understanding) are paired with a unique motivation for interpersonal interactions which, in turn, espouse more advanced representational thinking (Tomasello, et al., 2005). Taken together, children's acquisition of social-cognitive competencies likely involves a language-mediated mechanism, but there may also be a pathway that is independent from language-based processing (see Jenkins \& Astington, 1996). 


\subsection{Distal and Proximal Social-Environmental Influences on Social-Cognitive Development}

A socio-cultural perspective on the development of social cognition implies more than simply examining parental influences on children. Bronfenbrenner (1979) argued that development occurs within embedded 'layers' of context. The proximal layer of influence involves the relationships in which the child takes part and includes processes in parenting described above (e.g., attunement). Such proximal influences are embedded within distal structures, such as the economic and cultural communities that have a bearing on the way parents carry out parenting tasks. Models that test the way in which distal factors are associated with children's outcomes through proximal processes have been referred to as indirect effect or mediation models (MacKinnon, Fairchild, \& Fritz, 2007). As they take account of multiple levels of influence simultaneously, these models provide a more comprehensive account of the ways in which distal and proximal aspects of the environment are associated with development.

Social disadvantage, broadly construed, is the distal factor most strongly associated with early development. Distal risks that have been linked to aspects of social cognition include socioeconomic disadvantage (Bradley \& Corwyn, 2002), low parental education (Cutting \& Dunn, 1999), single- and step-family status (Amato, 2001), parental psychiatric health (Rohrer, Cicchetti, Rogosch, Toth, \& Maughan, 2011), and adversity in the parents' background (Bailey, DeOliveira, Wolfe, Evans, \& Hartwick, 2012). However, single distal risks do not capture the degree of risk exposure experienced by children. For example, Dong et al. (2004) investigated the co-occurrence of 10 environmental risks, and found that these risks were significantly more likely to occur together than to occur alone. Cumulative risk indices have been constructed to test the idea that development is affected by the accumulation of environmental risk rather than the occurrence of a single and specific risk. Indeed, cumulative risk measures have been found to explain more variance in child outcomes than any single factor (Flouri \& Kallis, 2007). It is also notable that, across studies, cumulative risk indices combine different risks together, yet the prediction from cumulative risk to child outcome remains similar (Rutter, 1979; Sameroff, 2000). This suggests that it is the overall extent of disadvantage that has a bearing on children's development, rather than the specific effect of a single type of disadvantage.

As risks accumulate, parents' ability to provide support, attention, and sensitivity to their children is reduced (Ayoub, et al., 2009; Burchinal, Vernon-Feagans, Cox, \& Investigators, 
2008; Burchinal, Roberts, Zeisel, \& Rowley, 2008). Higher levels of cumulative risk have been found to be associated with lower levels of effortful control and social competence in the preschool period (Lengua, Honorado, \& Bush, 2007), as well as poorer cognitive outcomes at 24 months (Cabrera, Fagan, Wight, \& Schadler, 2011). Furthermore, support has been found for the pathway from cumulative risk to negative child outcomes through problematic parenting. It has been shown that cumulative risk operates indirectly through mothers' sensitivity and responsivity to influence children's socioemotional functioning (Cabrera, et al., 2011), their internalizing and externalizing problems (Trentacosta, et al., 2008), and their social competence (Lengua, et al., 2007). Further, Burchinal, Vernon-Feagans et al. (2008) reported that cumulative risk was associated with cognitive outcomes through mother's sensitivity and warmth in children as young as 15 months.

Although the above studies have documented the indirect effect of cumulative risk on children's general cognitive ability and social competence through parenting, no previous study has examined such a pathway for children's understanding of intentionality at 18 months. Links between parenting and child behaviours that reflect intention understanding (e.g. joint attention, empathy, and cooperation) have been investigated, although predictors of the general construct have not been examined. These studies have led to the conclusion that parental responsivity including sensitivity, mutuality, and patient explanation - foster children's joint attention (Gaffan, Martins, Healy, \& Murray, 2010), empathy (Kiang, Moreno, \& Robinson, 2004), cooperation (NICHD, 1999), and self-recognition (Keller, Kärtner, Borke, Yovsi, \& Kleis, 2005).

\subsection{Goals of the Present Study}

We test a model in which cumulative environmental risk influences social cognition at 18 months through its effect on parenting. In developing a cumulative risk index, we selected indicators known to be associated with parenting difficulties and more troubled child behaviour: low maternal education, maternal depression, mothers' history of physical and sexual abuse, family structure (step- or lone-parents), and a lack of organization and safety in the home environment. We hypothesized that cumulative risk would be indirectly related to social cognition through responsive parenting. Consistent with Vygotskian theory, strong links have also been shown between language and social cognition (Astington \& Jenkins, 1999; Hale \& Tager-Flusberg, 2003). Social risk has been shown to influence children's language indirectly 
through maternal responsiveness (Raviv, Kessenich, \& Morrison, 2004). Since maternal responsiveness is related to language development, and since language skills are associated with social cognition, a second hypothesis of the present study is that part of the effect of responsivity on social cognition will operate through children's concurrent language ability. The direct effect from cumulative risk to social cognition was not hypothesized given that direct relationships between social disadvantage and social cognition have been found to be inconsistent (see Lucariello, Durand, \& Yarnell, 2007).

\section{Methodology}

\subsection{Participants}

All women giving birth to infants in the cities of Toronto and Hamilton between February 2006 and February 2008 were considered for participation. Families were recruited through a program called Healthy Babies Healthy Children, run by Toronto and Hamilton Public Health Units, which contacts the parents of all newborn babies within several days of the newborn's birth. Inclusion criteria for participation in the Intensive sample of the Kids, Families and Places (IKFP) study included an English-speaking mother, a newborn $>1500$ grams, and two or more children $<4$ years old. Thirty-four percent of families approached agreed to take part. At Time 1 (T1; infants were 2 months old), 501 families took part in the intensive sample data collection. These families were followed up at Time 2 (T2), at which point the youngest child in each family was about 18-months-old. Since we were interested in social-cognitive outcomes at 18 months, only the youngest child in each family was included in the present study, as including older siblings would have changed this target age significantly. Thus, the final sample consisted of 501 children, one per family in the IKFP sample. The mean age of children at T2 was 1.60 years (SD $=0.16$ ). There were 254 boys and 247 girls.

We compared the IKFP sample with the general population of Toronto and Hamilton using 2006 Canada Census Data, limiting the census data to women between 20-50 years and having at least one child. The comparison was based on five indicators: immigrant status, number of persons in the household, family type, and mother-reported income and education. The IKFP sample was similar to the general population in terms of number of persons in the household $(M=4.52, S D=$ 1.01 versus $M=4.13 ; S D=1.22)$ and personal income $(\$ 30,000-39,999$ versus census population mean $=\$ 30,504.16, S D=\$ 37,808.12)$; however, the IKFP sample had fewer non- 
intact families (lone-parent: $5 \%$ versus $16.8 \%$; step-families: $4.3 \%$ vs. $10.3 \%$ ), fewer immigrants ( $47 \%$ versus $57.7 \%$ ), and more educated mothers (53\% had a Bachelor's degree compared to $30.6 \%$ in the general population).

\subsection{Procedure}

Data collection at $\mathrm{T} 1$ included both questionnaire and observational measures. Trained interviewers visited each family's residence for approximately two hours. During the visit, mothers completed several questionnaires that tapped into the items included in the cumulative risk index. Interviewers also made observations of the home environment. At T2, families were again visited for about two hours. During this time, mothers were observed interacting with their children in two separate tasks - an unstructured play period involving no toys, and a semistructured task involving toys. These interactions served as the basis for measuring mothers' responsivity. At T2 children also participated in a variety of behavioural tasks designed to measure different aspects of social cognition, as described below. These included joint attention, empathy, cooperation, and self-recognition.

\subsection{Measures}

\subsubsection{Cumulative Risk Index}

The cumulative risk index was based on five contextual risks, all assessed at T1 (except for marital status; see below). These risks have been shown in previous studies to predict negative outcomes in children, and have also been used as a cumulative risk index in other studies from this project (Meunier, Jenkins, Boyle, \& O'Connor, 2011). Following previous studies (Whipple, Evans, Barry, \& Maxwell, 2010), the dichotomous classification of risk exposure was determined by a statistical cut-off (e.g., $25^{\text {th }}$ percentile) for the continuous variables and on the basis of existing categories for the categorical and dichotomous variables. Risk for each individual variable was assigned a value of 1 ; no risk was assigned a value of 0 . The variables included in the cumulative risk index were as follows (see Introduction for evidence of the impact of these social risks on parenting and child outcomes). 


\subsubsection{Mothers' educational level}

Mothers reported on the number of years of education they completed, including secondary and postsecondary education. The mean educational level was 15.41 years $(S D=2.66$, range $8-22)$. The selected cut-off was 12.98 .

\subsubsection{Maternal Depression}

Mothers' depressive symptomatology (hereafter referred to as 'maternal depression') was assessed using the Center for Epidemiological Studies Depression Scale (CES-D, Radloff, 1977). This is a self-report scale designed to assess depression in nonclinical populations. Respondents rate the frequency of 20 depressive symptoms over the past week using a 4-point scale. The scale showed high internal consistency $(\alpha=0.84)$ and substantial stability $(r=0.53, \mathrm{p}<0.001)$ between T1 and T2. The established cut-off was 12.07.

\subsubsection{Maternal history of physical and sexual abuse}

Mothers' reported on their history of physical and sexual abuse using the Childhood Experience of Violence Questionnaire (CEVQ, Walsh, MacMillan, Trocme, Jamieson, \& Boyle, 2008). The CEVQ measures mothers' childhood exposure to violence. Since the CEVQ was initially developed for youth between 12- to 18-years-old, we adapted the items for adults. The measure shows good reliability and validity (Walsh, et al., 2008). Physical abuse items included 'how many times before the age of 16 did an adult caregiver: (1) slap you on the face, head or ears, or hit you with a hard object, such as a belt, stick, or wooden spoon; (2) push, grab, shove or throw something at you to hurt you; and (3) kick, bite, punch, choke, burn you, or physically attack you in some way'. Response options were 'never', ' 1 or 2 times', ' 3 to 5 times', ' 6 to 10 times' and 'more than 10 times'. Sexual abuse was assessed by two questions: 'Before age 16, were you ever sexually assaulted or raped?' If yes: 'How many times did this happen?' Since scales were highly skewed with most mothers reporting no experiences of abuse, we recoded the scales to be dichotomous by following the natural cut point of the distribution. A cut-off of 2 was utilized for physical abuse (representing 12.6\% of the sample) and a cut off of 1 was used for sexual abuse (9.3\%). A report of physical and/or sexual abuse during childhood (18.8\% of mothers) was coded as ' 1 '. 


\subsubsection{Organization and safety}

Interviewers rated the quality of the home environment using an adapted version of the Home Observation for Measurement of Environment scale (HOME, Bradley \& Caldwell, 1981). The original HOME scale combines both observer ratings and maternal reports of the environment. The present study required only an observational rating, and thus only items rated by the independent observer were included. In total, 12 items were rated by observers on a 3- or 4-point scale. Preliminary factor analysis revealed two factors with eigenvalues greater than 1 that explained $44 \%$ of the variance. Of the 12 items used in the present study, ten loaded above 0.4 , with no higher cross-loadings on another factor. A first factor (including 4 items) represented organization, cleanliness, and safety of the physical environment. The second factor (including 6 items) reflected the amount of playing and learning tools available to the children. Only the organization and safety construct was used in the present study because this variable was believed to represent a risk that would compromise mothers' provision of responsive parenting. That is, this variable parallels a measure of household 'chaos' that is known to be associated with negative parenting behaviours (Coldwell, Pike, \& Dunn, 2006; Dumas, et al., 2005). Internal consistency for the organization and safety measure was good $(\alpha=0.79)$. Inter-rater reliability was assessed on $20 \%$ of the sample, and agreement across raters was high ( $r$ ranged from 0.90 to 0.94). Finally, the correlation between $\mathrm{T} 1$ and $\mathrm{T} 2$ measures showed relatively high stability $(r=$ $0.44, \mathrm{p}<0.001)$.

\subsubsection{Family Type}

In the current study, information about family structure was taken from the second assessment period since there was more change in this risk than in others (i.e., family type status changed for 16 families: 3 two-parent to step families; 8 two-parent to lone-parent families; 1 step to loneparent family; 4 lone-parent to step families). Family structure was coded into two-parents (0), lone-parent or step families (1), which represented $11.5 \%$ of families.

\subsubsection{Final Risk Index}

The cumulative risk index thus ranged from 0 to 5 . From the total sample, $42.3 \%$ presented no risk (0), $31.2 \%$ presented one risk (1), $16.1 \%$ presented two risks (2), $10.3 \%$ presented three or more risks (3-5). 


\subsubsection{Maternal Responsivity}

Observational data were gathered at $\mathrm{T} 2$ on parent-child interactions during tasks that elicited a range of behaviours from both members of the dyad, including an unstructured free play task, a structured cooperative teaching task, and a wordless picture book task. Each task lasted five minutes. Three domains of responsivity were coded using the Parent-Child Interaction System of global ratings (PARCHISY, Deater-Deckard, Pylas, \& Petrill, 1997) and the Coding of Attachment Related Parenting (CARP, Matias, 2006). The sensitivity code (CARP) measured the degree to which the parent responded to the child's verbal and non-verbal signals, supported the child's autonomy, showed warmth, and demonstrated an ability to see things from the child's point of view. Mutuality (CARP) is a dyadic code and is compatible with the concept of the "goal-corrected partnership" (Bowlby, 1982). Mutuality was indexed by reciprocity in conversation (e.g., a conversation that "goes somewhere" and is a genuine dialogue), affect sharing, joint engagement in task, and open body posture. Positive control (PARCHISY) captures the parents' positive means of getting the child to do something that she wanted him or her to do through the use of praise, open ended questions, rewards, and explanations. Each of these three domains - sensitivity, mutuality, and positive control - was rated on a 7-point scale, with higher scores indicating higher levels of that behaviour. A total of $10 \%$ of the interactions were double-coded for reliability purposes. Inter-rater reliability was high $(\alpha=.940)$. These three measures were used to create a latent variable that we have termed 'maternal responsivity'.

\subsubsection{Social Cognition}

Children's social cognition was assessed at T2 (children were 18-months-old) by measuring several social-cognitive skills that represented different forms of intention understanding (see Introduction). These skills were as follows:

\subsubsection{Joint Attention}

This was measured in terms of children's ability to follow the gaze of an adult interviewer (Carpenter, Nagell, et al., 1998), using a gaze-following task from the Early Social Communication Scale (ESCS; Mundy, et al., 2003). The child sat with his or her mother across from the experimenter. Four colourful pictures had been placed to the side (2) and behind the child (2). The tester first ensured she had the attention of the child by calling the child's name, tapping the table, or gently touching the child. She then proceeded to point to the four posters in 
a systematic order: tester's Left, Left-Behind, Right, Right-Behind. The point consisted of the tester turning her entire torso, visually orienting to a poster and keeping her elbow in contact with body. During the pointing trial, if the child did not immediately redirect his or her attention to the poster, the tester proceeded to say the child's name three times. If the child still did not redirect his or her attention, the tester paused before redirecting attention to the child. This task was administered twice throughout the home visit, separated by another activity, for a total of 8 possible 'respond-to-joint-attention' (RJA) observations for each child. A trained coder viewed videotapes and coded children's ability to redirect attention to the focal object along a 4-point scale. If the child immediately redirected attention to the poster after the tester's point, the child received a score of 4 . If the child redirected attention after the tester said his or her name, the child received a score of 3 . If the child delayed redirection of attention until after the tester's point was finished, but before the next trial commenced, the child received a score of 2 . If the child failed to redirect attention to a poster, he or she received the lowest score of 1 . Inter-rater reliability of $11 \%$ of the videotapes was $\alpha=0.94$. A task analysis revealed significant mean differences between side point $(M=3.90, S D=0.27)$ and behind point $(M=3.30, S D=0.91)$ trials $(t(279)=11.77, p<0.01)$, suggesting that following side points is a simple task for most 18-month olds. Furthermore, only behind points correlated significantly with children's concurrent vocabulary $(r=.22, p<0.01)$, indicating more robust construct validity for the behind-points in the current sample. Thus, for each child, only the 4 observations of the behind trials were used as the measure of RJA. Videotapes from 115 of the 358 children who were administered the behind-point trials could not be coded due to non-administration, child noncompliance, lack of visibility (e.g., child went off camera), mother intrusion (e.g., directing her child's attention), or tester administration error (e.g., not following standardized protocol).

\subsubsection{Empathy}

This was measured as the child's responsiveness to the feigned distress of an adult interviewer. At standard points during the home interview, the interviewer pretended to hurt her knee and finger, as well as to drop and ostensibly break her favourite toy (at start of testing child met 'Mickey', a monkey magnetic toy, whose head is later knocked off accidently). Two coders watched all empathy events and rated children on six statements based on their reaction to the interviewer's distress. A thin-slice coding method was used (Ambady, Bernieri, \& Richeson, 2000; Ambady \& Rosenthal, 1992), which is a global or impressionistic rating of the child's 
behaviour. This method has been used successfully in rating child behaviour (Prime, Perlman, Tackett, \& Jenkins, 2011). Based on the thin-slice methodology, coders are encouraged to make general judgements about children using all available information from the empathy events, and their final ratings are averaged to decrease the impact of a single observer's judgment (Ambady, et al., 2000). We used an adaptation of an empathy scale developed by Kochanska and colleagues (Kochanska, DeVet, Goldman, Murray, \& Putnam, 1994) on which to base our ratings. Five items were removed from the scale because they referred to elicitors for which our raters had no information (reactions to movie characters or animals being hurt). Items rated included 'Will try to comfort or reassure another in distress'; 'Likely to offer toys or candy to crying playmate even without parental suggestion'; 'Can tell at just one glance how others are feeling'; 'Likely to ask what's wrong when seeing someone in distress'; 'Will feel sorry for other people who are hurt sick or unhappy'; and 'Is not likely to become upset if a playmate cries'. The internal consistency was 0.978 for coder 1 and 0.956 for coder 2. Although inter-rater agreement in thin-slice methodology is not normally reported, agreement between coders was high ( $\alpha=$ $.824)$.

\subsubsection{Cooperation}

Children's cooperation skills were measured with two previously developed cooperation tasks: trampoline and double tube (Warneken, et al., 2006). These tasks assess the extent to which children will cooperate with the tester towards a goal, requiring the child to change his/her behaviour to succeed. In the trampoline task, the child was invited by the tester to help her make a bear dance on a hand-held trampoline, and thus the child was required to replicate the same behaviour as the tester. Discrete 10-second intervals were coded on a 5-point scale, up to a maximum of 80 seconds. The scale ranged from 1 (no success/engagement) to 5 (high engagement), and the mean of intervals was taken. In the double tubes tasks, the child was invited to help the experimenter complete a sequence of actions in which she rolled a ball down one of two tubes and asked the child to catch it at the bottom. In contrast to the trampoline task, the child is required to engage in different but complementary behaviour to the tester to achieve the goal. After one practice, each catch invitation was coded on a 5-point scale, with a maximum of 8 trials coded. The scale ranged from 1 (no attempt) to 5 (complete success). A mean of each child's scores on the double tubes catch trials was derived. After each of the trampoline and double tubes tasks were completed, coders rated a global cooperation score, or the overall extent 
to which the child was cooperative and engaged with the tester. The global cooperation score was coded along a 4-point scale (quartiles), based on percentage of the task the child was cooperative. Finally, after tasks were completed, coders also provided a global rating of lack of cooperation from 'none' (0) to '3 or more times' (3); the items were reverse coded. Ten percent of videotapes were double coded by independent coders and the mean inter-rater reliability across all cooperation tasks was $\alpha=0.86$ (ranging from 0.68 to 0.96 ). All of the items loaded significantly onto the same factor, explaining $47 \%$ of the variance, with item loadings ranging from 0.54 to 0.76 . A composite cooperation variable was constructed by taking the mean of the tasks' standardized scores. Internal consistency of the five items making up the composite was $\alpha$ $=0.71$.

\subsubsection{Self-Recognition}

During the cooperation task, the interviewer surreptitiously marked the child with a large coloured sticker at the front of their head on the hair (so that they could not feel it being placed). The child was then placed in front of a mirror and allowed to look at themselves for 30 seconds. This was a dichotomous code. If the child demonstrated any self-directed behaviour (either reaching for the sticker or verbally acknowledging its presence, with or without prompting), the child received a score of 1 . If the child did not recognize the sticker at all, they received a score of 0 . Thus, this score was a conservative estimate of the child's ability to recognize him/herself in the mirror.

\subsubsection{Language}

The MacArthur-Bates Communicative Development Inventories (CDI) was used at T2 to measure children's language ability (Fenson, et al., 1994). The CDI is a mother-reported measure of children's expressive vocabulary. Mothers report on both English and the child's heritage language, and we took the maximum score. Studies of the CDI have shown that it is a valid and reliable measure for typically-developing children (Dale, 1991; Dale, Bates, Reznick, \& Morisset, 1989), children with language delays (Heilmann, Weismer, Evans, \& Hollar, 2005), and children who are older than the age range on which the CDI was normed, but who have language skills paralleling the children in the norming range (Thal, O'Hanlon, Clemmons, \& Fralin, 1999). 


\subsection{Plan of Analysis}

First, descriptive statistics and bivariate relationships among the measures were examined. Although the primary distal predictor was a cumulative risk index, these indices can mask the effects of single variables within the index. As a result, we have included all individual variables that comprised the cumulative risk index in the tables and correlation matrix. We also included all variables that were used as indicators of the social cognition construct and maternal responsivity construct, even though these were unobserved latent variables in the main analysis.

The analysis was carried out using Mplus, version 6.1 (Muthén \& Muthén, 2010). First, the measurement model for social cognition was tested. Second, structural equation modelling (SEM) was carried out to examine the hypothesized indirect effects, even though the direct effect of cumulative risk to social cognition was not expected to be significant. This process examining the indirect effect of the predictor through the hypothesized mediator even when the predictor-outcome association is not present - is advisable when the theoretical model suggests such a mechanism (MacKinnon, Lockwood, Hoffman, West, \& Sheets, 2002). Indirect effects were tested using the delta method (Sobel, 1982), which is the default in Mplus 6.1. The delta method calculates the standard error of the product of two variables, which can then be used to determine the significance of the indirect path. This method is widely used in applied statistics for obtaining approximate standard errors and confidence intervals of parameters in SEM (Raykov \& Marcoulides, 2004). We report standardized direct and specific indirect effects for the structural model.

Full information maximum likelihood estimation (FIML) was utilized for all analyses. This method offers significant improvements over traditional approaches for handling missing data (Acock, 2005). For structural equation modelling, FIML has been shown to be superior to listwise deletion, pairwise deletion, and imputation in terms of convergence, parameter bias, and model fit (Enders \& Bandalos, 2001). For the current study, maximum likelihood estimation with robust standard errors (MLR) was chosen because it produces maximum likelihood parameter estimates with standard errors and a chi-square statistic that are robust to non-normality and nonindependence of the observations when missing data are present (Muthén \& Muthén, 2010). 


\section{Results}

\subsection{Preliminary Analysis}

The means and standard deviations of the measures and the bivariate correlations between the measures are reported in Table 1. As expected, the cumulative risk index was significantly associated with all measures of maternal responsivity in the expected direction. Moreover, all three aspects of maternal responsivity were related to cooperation, self-recognition, and language. Only mutuality was significantly associated with children's joint attention abilities, whereas none of the parenting measures were associated with children's empathy. All of the social-cognitive skills were significantly related to one another in the expected direction with the exception of empathy and self-recognition, which were not significantly associated with one another.

\subsection{Testing the Measurement Model for Social Cognition}

Confirmatory factor analysis (CFA) was used to examine the factor structure for the social cognition and maternal responsivity latent variables. Before conducting the factor analysis, each of the continuous indicators of social cognition (joint attention, empathy, and cooperation) was screened for normality and outliers. Neither cooperation nor empathy exceeded the cutoff values of 2 for skewness or 7 for kurtosis (West, Finch, \& Curran, 1995). However, our joint attention variable was negatively skewed (i.e. many children demonstrated high joint attention skills). This finding was not surprising given that joint attention skills emerge around 9 months, and thus many children would be expected to show this ability by 18 months. However, given the large sample size of the current study, there was still sufficient variability in this indicator to include it within the latent construct. Regarding the concern of non-normally distributed variables, it has been shown that maximum likelihood (ML) methods show little bias in estimates of factor loadings in confirmatory factor analysis (Benson \& Fleishman, 1994), as well as estimates of structural coefficients and indirect effect estimates in structural equation models (West, et al., 1995). Maximum likelihood estimation with robust standard errors (MLR) provides ML

parameter estimates with standard errors and an adjusted $\chi^{2}$ test statistic that are robust to deviations from normality (Brown, 2006). These findings support our use of MLR for the CFA and structural model without requiring variable transformation. 


\begin{tabular}{|c|c|c|c|c|c|c|c|c|c|c|c|c|c|c|c|c|c|c|}
\hline Measures & 1. & 2. & 3. & 4. & 5. & 6. & 7. & 8. & 9. & 10. & 11. & 12. & 13. & 14. & 15. & $N$ & $M$ & $S D$ \\
\hline \multicolumn{19}{|l|}{ Distal Maternal Risk } \\
\hline 1. Education Level & - & & & & & & & & & & & & & & & 500 & 15.27 & 2.68 \\
\hline 2. Step Family & $-.21 * *$ & - & & & & & & & & & & & & & & 397 & - & - \\
\hline 3. Lone Parent & $-.24 * *$ & - & - & & & & & & & & & & & & & 397 & - & - \\
\hline 4. Maternal Depression & $-.25 * *$ & .02 & $.16^{* * *}$ & - & & & & & & & & & & & & 493 & 9.45 & 7.29 \\
\hline 5. Maternal History of Abuse & $-.13 *$ & $.19 * *$ & $.18 * *$ & $.18 * *$ & - & & & & & & & & & & & 388 & 0.22 & 0.48 \\
\hline 6. Organization/Safety & $.22 * *$ & -.09 & $-.15 * *$ & $-.14 * *$ & $-.22 * *$ & - & & & & & & & & & & 395 & 2.52 & 0.59 \\
\hline 7. Cumulative Risk Index & $-.53 * *$ & $.35^{* *}$ & $.42 * *$ & $.52 * *$ & $.57 * *$ & $-.54 * *$ & - & & & & & & & & & 397 & 0.99 & 1.12 \\
\hline \multicolumn{19}{|l|}{ Maternal Responsivity } \\
\hline 8. Sensitivity & $.25 * *$ & -.09 & $-.17 * *$ & $-.13 *$ & -.07 & $.13^{*}$ & $-.22 * *$ & - & & & & & & & & 372 & 4.03 & 0.92 \\
\hline 9. Mutuality & $.21 * *$ & $-.11 *$ & $-.18 * *$ & $-.14 * *$ & -.04 & $.15 * *$ & $-.22 * *$ & $.70 * *$ & - & & & & & & & 372 & 3.47 & 0.90 \\
\hline 10. Positive Control & $.22 * *$ & -.07 & $-.16 * *$ & $-.15 * *$ & $-.12 *$ & $.18 * *$ & $-.24 * *$ & $.63 * *$ & $.60^{* *}$ & - & & & & & & 372 & 3.04 & 0.90 \\
\hline \multicolumn{19}{|l|}{ Child Social Cognition } \\
\hline 11. Joint Attention & -.09 & -.00 & -.09 & -.03 & .00 & -.04 & -.02 & .05 & $.14^{*}$ & .03 & - & & & & & 317 & 3.65 & 0.50 \\
\hline 12. Empathy & .03 & .02 & .04 & .06 & .05 & .10 & -.04 & .02 & .10 & -.02 & $.19^{* *}$ & - & & & & 322 & 3.53 & 1.10 \\
\hline 13. Cooperation & .06 & -.02 & -.05 & -.07 & -.03 & .10 & -.09 & $.23 * *$ & $.32 * *$ & $.16^{* *}$ & $.17^{* *}$ & $.19 * *$ & - & & & 364 & -0.59 & 0.63 \\
\hline 14. Self-Recognition & .10 & -.09 & .02 & -.01 & .02 & .09 & -.08 & $.11^{*}$ & $.13^{*}$ & .11 & $.21^{* *}$ & .07 & $.23 * *$ & - & & 325 & 0.40 & 0.49 \\
\hline 15. Language & .02 & -.07 & .06 & .04 & .05 & .08 & -.00 & $.11 *$ & $.19^{* *}$ & $.15^{* *}$ & $.14 *$ & $.16^{* * *}$ & $.20 * *$ & $.18^{* * *}$ & - & 366 & 0 & 0.99 \\
\hline
\end{tabular}

$* p<.05 . * * p<.01$

Table 1. Correlations, mean scores, standard deviations, and number of participants for study variables 
The social cognition latent factor was indicated by joint attention, empathy, cooperation, and self-recognition; and the maternal responsivity factor was indicated by sensitivity, mutuality, and positive control. As recommended by Cole and Maxwell (2003), these two latent factors were allowed to correlate with one another in the measurement model. The measurement model fit the data well: comparative fit index $(\mathrm{CFI})=0.97$, Tucker-Lewis index $(\mathrm{TLI})=0.95$, standardized root-mean-square residual $(\mathrm{SRMR})=0.042$, and root-mean-square-error of approximation $($ RMSEA $)=0.058$. The 90\% confidence interval for RMSEA was [0.030, 0.086], and PCLOSE (i.e. the probability that RMSEA $\leq 0.05)$ was 0.29. Hu and Bentler (1999) have recommended goodness of fit cut-off values of 0.95 for CFI and TLI, 0.08 for SRMR, and 0.06 for RMSEA. All of the abovementioned fit indices for the measurement model were either equal to or better than these recommended cut-offs. Furthermore, all of the model-estimated loadings onto each latent were positive and significant at the $p<0.001$ level. For the social cognition latent, the standardized regression coefficients for each of these loadings were 0.35 for joint attention, 0.28 for empathy, 0.64 for cooperation, and 0.40 for self-recognition. For the maternal responsivity latent, the loadings were 0.85 for sensitivity, 0.83 for mutuality, and 0.73 for positive control (see Figure 1). Thus, the test of the measurement model showed that the manifest variables related to one another in the way we had hypothesized.

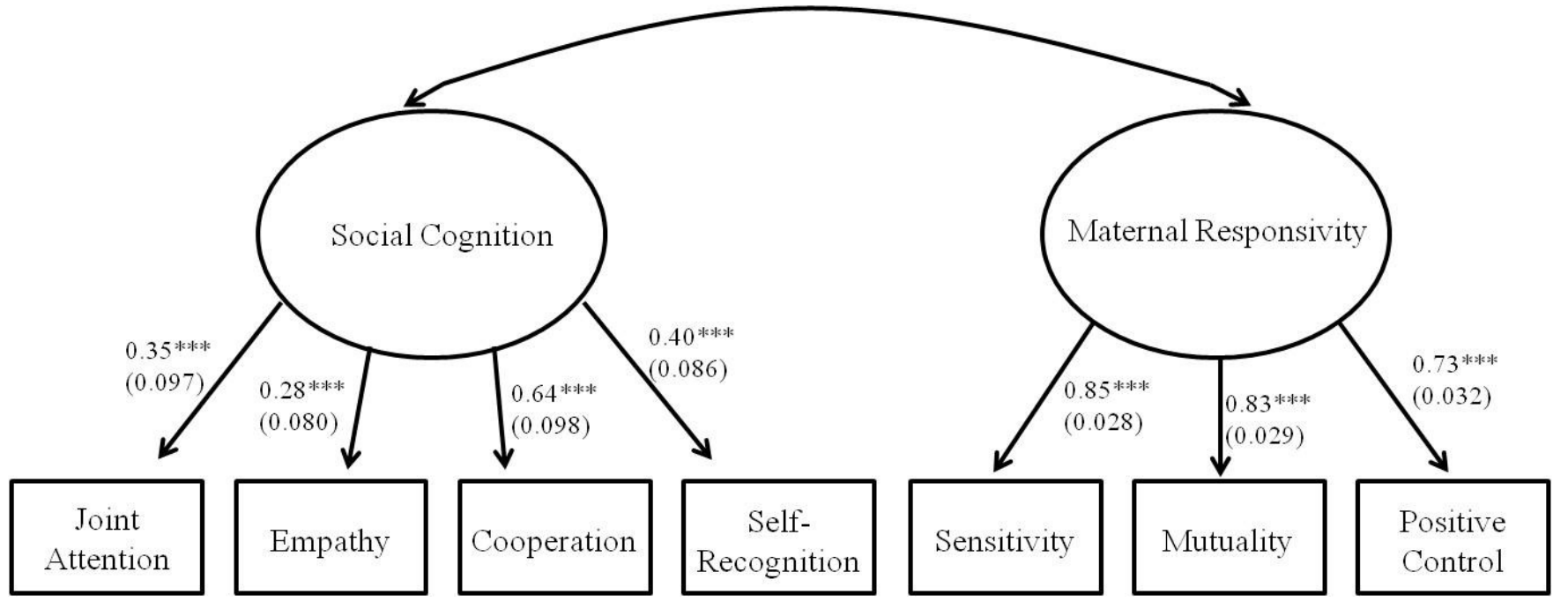

Figure 1. Measurement model for the social cognition and maternal responsivity latent constructs. For social cognition, each of the indicators is a skill that indexes the ability to understand the independent experiences of others, or the objectivity of oneself. Joint attention, empathy, and cooperation reflect different forms of intention understanding. Each loading can be interpreted as a standardized regression coefficient. All loadings for each latent were significant at the $p<.001$ level. 


\subsection{Testing the Proposed Indirect Paths - The Structural Model}

The structural model was tested next. The hypothesized model fit the data well: CFI $=0.97$, TLI $=0.96, \mathrm{SRMR}=0.039$, and RMSEA $=0.042$. The 90\% confidence interval for RMSEA was $[0.016,0.065]$, and the PCLOSE value was 0.70 . Since there was slight variability in children's age at $\mathrm{T} 2$, we also ran the model covarying age with social cognition. The model fit remained acceptable for all indices.

Regarding the hypothesized indirect effects, the indirect effect of cumulative risk at T1 on social cognition through maternal responsivity at T2 was significant $(z=-3.07, p=0.002)$. Thus, cumulative risk is associated with lower maternal responsivity which is, in turn, related to lower social-cognitive ability. Also, there was a significant indirect effect from cumulative risk to maternal responsivity to social cognition that operated through children's language at T2 $(z=-$ 2.32, $p=0.020$ ). That is, cumulative risk was associated with lower responsivity, lower responsivity was associated with less advanced language skills, and lower language was related to poorer social cognition (see Figure 2). As hypothesized, there was no direct association between cumulative risk at T1 and children's social cognition at T2 $(\beta=-0.059, p=0.45)$. Collectively, this means that the effect of cumulative risk on social cognition operated through maternal responsivity, and that some of the effect of cumulative risk through maternal responsivity operated via children's language.

\subsection{Secondary Analysis}

As language and social cognition were measured concurrently in the present study, we examined the possibility that the indirect effects reported above remained when language and social cognition were reversed in the structural model - that is, contextual risk operated through social cognition to affect child language. Fit indices were similar. Indeed, there was a significant indirect effect of cumulative risk to maternal responsivity to language that operated through social cognition $(z=-2.56, p=0.010)$. The indirect effect of cumulative risk to language through responsivity (i.e. not going through social cognition) was not significant $(z=-0.67, p=0.505)$. 


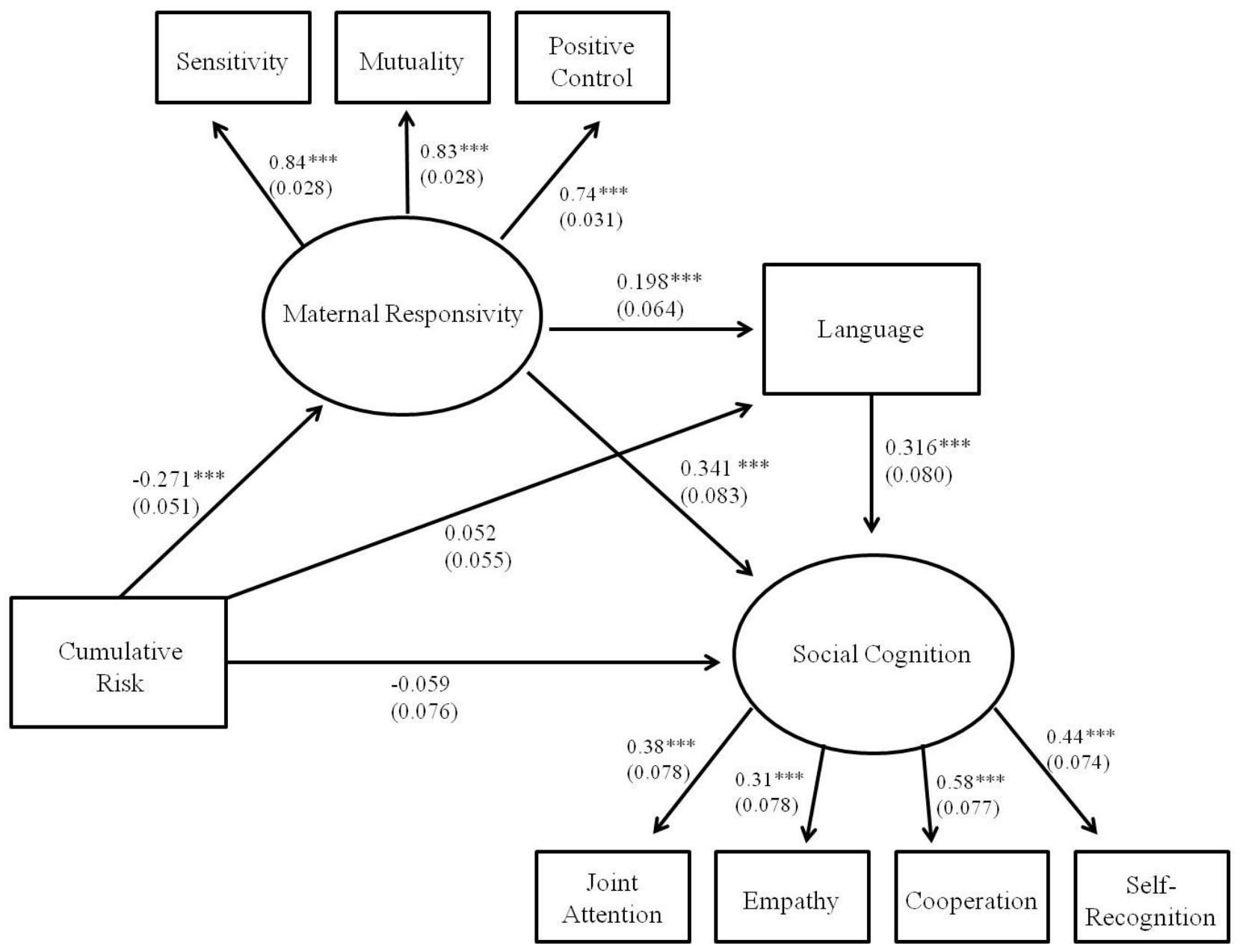

Figure 2. Hypothesized model on the relations between distal cumulative risk, maternal responsivity, child language, and social cognition at 18 months. Standardized regression coefficients are presented atop each path line (standard errors are presented in brackets). Paths that are significant at the $p<.001$ are indicted by $* * *$; all other paths are not significant. 


\section{Discussion}

\subsection{Interpretation of the Results}

The current study was designed to investigate links between contextual adversity and children's early social cognition, which was operationalized as a set of commonly measured 'skills' that reflect children's understanding of intentionality at 18 months. First, it was shown that cumulative social risk measured when children were newborns was indirectly associated with their social cognition at 18 months through maternal responsivity. This is interesting considering that some models of social-cognitive development have posited an innate, genetically-prescribed mechanism that is responsible for children's emergent understanding of others (Leslie, 1994). However, these findings are consistent with the idea that interpersonal exchanges may scaffold children's understanding of mind - that is, social experience may shape children's cognitions (see Fernyhough, 2008). From this perspective, social cognition may actually be restructured by the internalization of multiple perspectives that are derived from interactions with others (Tomasello, et al., 2005).

Primary among those interactions early in life are the ones that occur with caregivers. The current results suggest that when parents are responsive to their child's needs, facilitate engagement in activities, and provide explanations and questions during social exchanges, they may actually be offering the alternative orientations toward reality which are important for the internal reconstruction of cognition that promotes the representation of mental states. At the same time, parents differ in their parenting behaviours based on an array of social circumstances. Mothers who were abused as children (Banyard, 1997; Silvern, 1994), are single (Martinez Jr \& Forgatch, 2002), have low education (Brody \& Flor, 1998), suffer from depression (Lovejoy, Graczyk, O'Hare, \& Neuman, 2000), and whose home environments are chaotic and disorganized (Dumas, et al., 2005) are more likely to provide negative forms of care. Indeed, many of these distal risks co-occur with one another. Bronfenbrenner's ecological perspective of development urges the use of process-oriented research that identifies relationships between these distal ecological factors, proximal processes, and child outcomes (Bronfenbrenner \& Morris, 2006). In line with this view, the current study is the first to show that an accumulation of social risks compromises mothers' ability to provide sensitive and responsive care to her child which, in turn, adversely affects social-cognitive skill development at 18 months. These results 
are consistent with the notion that it is the extent of disadvantage, rather than exposure to individual risks, that is detrimental to children's outcomes (Dong, et al., 2004; Trentacosta, et al., 2008).

It is important to discuss the elements of parenting measured in the current study and speculate on how those behaviours might foster children's social cognition. The components of responsivity in the current study were sensitivity, mutuality, and positive control. All of these dimensions of parenting made contributions to the responsivity latent construct, and each was associated with the cumulative risk index. Thus, it appears that distal social risk impacts multiple dimensions of parenting behaviour, and these behaviours are in turn predictive of children's social cognition at 18 months. However, each component of parenting likely has differential yet complementary effects on social-cognitive development. For instance, elements of sensitivity in the present study included responsiveness to the child's verbal/non-verbal signals and maternal warmth. These behaviours may promote the child's motivation to take part in social interactions with others owing to the support and reinforcement that comes from such exchanges. Indeed, higher levels of maternal warmth have been shown to predict lower child negativity and more child engagement (Ispa, et al., 2004). When children are more engaged, other elements of sensitivity such as child mindedness (an awareness of their child's internal mental states), facilitation, and autonomy-promotion can then provide the alternative perspectives that enhance social cognition. For example, when a mother facilitates her child by offering an alternative solution to a problem, or when she encourages her child to try different strategies, she is providing ideas that the child may not have realized on their own. The same is true for positive control, which consists of giving praise, explanation, and asking open-ended questions. For instance, asking the child how they would like to begin a task suggests that there may be more than one way to start - a situation that promotes consideration of more than one perspective. Likewise, providing an explanation for a problem may expose the child to a level of reasoning that they could not achieve on their own. It is the cognitive challenge and opportunity to experience these different perspectives that facilitates children's representational thinking and social cognition early in life (Fernyhough, 2008).

The third dimension of responsivity measured in the current study was mutuality, a dyadic code that indexes the quality of interaction and reciprocity between mother and child. Mutuality included elements of parenting such as shared attention and affect, imitation, turn-taking, fluid 
conversation, and coordinated body orientation. How does mutuality promote children's social cognition? It may be that mutual interactions enhance the internalization of interpersonal experience. For example, Kochanska, Forman, Aksan, and Dunbar (2005) provide evidence for the idea that a mutually responsive orientation between a mother and her child augments the internalization of moral conduct and cognition, and this process is mediated by processes such as the child's enjoyment in the interaction. Together, these results suggest that different types of parenting behaviours come as a package, each making important (though perhaps different) contributions to children's social-cognitive development. There may also be complex and interrelated pathways through which different dimensions of responsivity facilitate children's social cognition. For instance, it has been shown that elements of sensitivity such as warmth and responsiveness predict higher dyadic mutuality in the second year (Ispa, et al., 2004). Examining the precise ways in which various parenting behaviours operate in the prediction of social cognition is an area that deserves attention in future research.

Another finding of the present study is that the effect of adversity on social cognition operated through children's concomitant language ability. That is, cumulative risk influenced parenting, which in turn was associated with social cognition at 18 months, both directly and indirectly through children's language skills. This result is consistent with the Vygotskian concept of semiotic mediation, in which psychological tools such as language augment children's ability to represent and reason about the mental states of others (Nelson, 2005; Vygotsky, 1997). It is also consistent with the proposal that social cognition depends on language acquisition and social experience (Garfield, Peterson, \& Perry, 2001), and the idea that internalization of dialogue involves the accommodation of multiple perspectives that facilitate social understanding (Fernyhough, 2008). Thus, children who have acquired the capacity for internalized dialogues are able to understand a range of differing epistemic, affective, and conative perspectives. This would manifest as improvements in the social-cognitive skills that rely on these forms of intention understanding (i.e. joint attention, empathy, and cooperation). From Fernyhough's (2008) standpoint, this does not mean that children as young as 18 months are capable of reflectively considering multiple perspectives involved in internal dialogue; but rather that emergent language faculties allow for partially internalized dialogues that precede a full-fledged understanding of mind. As language develops, the capacity to construct internal dialogues is enhanced, thus leading to more sophisticated forms of social understanding. 
To build on these ideas, the present study suggests that maternal responsivity may enhance the language skills which allow children to internalize the various perspectives that derive from those social interactions. Importantly, however, the effect of cumulative risk to social cognition through maternal responsivity did not operate exclusively through children's language. This means that there is a unique component of maternal responsivity involving sensitivity, mutuality, and positive control that is associated with social cognition. This component may simply entail the opportunity to experience alternative perspectives and orientations, or it may involve some other mechanism, such as improving attachment security or mother-child attunement (Meins, 2004). Future studies would benefit from conducting a more systematic examination of how aspects of parenting facilitate social cognition. Nevertheless, the results presented herein suggest that part of the influence of parenting on social cognition is its ability to foster early language skills, which may in turn accelerate the internalization of social experience.

One issue that requires elaboration is the relationship between social cognition and child language at 18 months. In the current study it was shown that there was an indirect path from cumulative risk to maternal sensitivity to language, which was then related to social cognition. These results are consistent with literature outlining the causal association between language and theory of mind ability (see Astington \& Baird, 2005). However, in the present study social cognition and language were measured concurrently at 18 months, and therefore we cannot discuss the casual influence of language on social cognition or vice versa. Indeed, it is possible that the ability to engage in dialogue is itself dependent on some social-cognitive capacities. For example, Morales and colleagues (2000) have shown that infants' joint attentional abilities at 6 months are positively related to their expressive vocabulary at 18 months. This finding parallels the proposition that the social-cognitive skills that underlie language development may themselves rely on it (Tomasello, et al., 2005). As shown in our secondary analysis, reversing language and social cognition in the structural model revealed that maternal responsivity also affected language through social cognition. Thus, early-emerging forms of social cognition appear to impact language development, and language provides the psychological tools required for the internalization of social experience that advances social cognition. These results speak to interdependent development of language and social cognition from infancy through the schoolage years (Astington, 2006). 


\subsection{Limitations and Future Directions}

One difficulty in interpreting the present result concerns inferences of causality. The optimal way of addressing causal influences is by measuring all constructs over time and examining crosslags. This was not possible in the present study since both maternal responsivity and social cognition were necessarily measured at the same time point. Specifically, we chose to examine social cognition and language at 18 months, which is the earliest stage at which these constructs can be reasonably measured (see above and Baldwin \& Moses, 1994). As a result, it is not possible to measure the effect of contextual adversity on social cognition (and language) after controlling for earlier levels of these abilities, as these abilities are not reliably observable prior to this age. This left us with the necessary but not sufficient condition of measuring cumulative risk at a time that preceded the emergence of maternal responsivity and the child's socialcognitive skills.

Finally, we have proposed that social cognition at 18 months be described in terms of children's capacity for understanding intentionality, which promotes engagement in shared social activities. However, we did not assess intention understanding using typical methods, such as imitation tasks where infants mimic accidental or intentional actions (e.g. Meltzoff, 1995), or habituation tasks that assess infant looking times (e.g. Csibra, Gergely, Biro, Koos, \& Brockbank, 1999)). Instead, we opted to measure a collection of social-cognitive skills that we believe reflect this underlying ability. We believe this approach has two advantages. First, examining multiple child behaviours simultaneously afforded us more power to measure various types of intention understanding, as outlined by Moore (2007); and second, these skills represent real social behaviours that have a bearing on children's interpersonal relationships and psychosocial health. Supporting this approach, there is evidence that each of the social-cognitive behaviours measured in the current study shares an underlying neural architecture that includes the paracingulate and orbitofrontal cotex (Kircher, et al., 2001; McCabe, Houser, Ryan, Smith, \& Trouard, 2001; Vollm, et al., 2006; Williams, Waiter, Perra, Perrett, \& Whiten, 2005). Consistent with the view that these social-cognitive skills represent an ability to understand and engage in intentional relations with others, Walter et al. (2004) showed that this same neural system is involved in understanding intentions during social interactions. Thus, we believe that the behaviours we chose to represent intention understanding sufficiently indexed that ability in our sample of 18month-old children. 
One area of research that is generating considerable interest is whether there are continuities in social cognition from infancy through childhood. For example, both action understanding at 6 months and putative intention understanding at 12 months have been linked to theory of mind ability when children are 4-years-old (Aschersleben, Hofer, \& Jovanovic, 2008; Wellman, Lopez-Duran, LaBounty, \& Hamilton, 2008). Perhaps unsurprisingly, the same neural system involved in basic intention understanding (i.e. the paracingulate cortex) has also been linked to theory of mind ability (Gallagher \& Frith, 2003). These findings are consistent with the notion that early forms of intention understanding may help shape the development of more advanced forms of social cognition later in childhood (Carpenter, Akhtar, \& Tomasello, 1998; Tomasello, et al., 2005). Given the results of the present investigation, future studies would benefit from examining the relationship between specific, observable social-cognitive skills and later theory of mind abilities (e.g. Charman, et al., 2000). If, in fact, these intention-related skills are related to further social-cognitive growth, then early efforts to promote skill development in these areas may prove effective in mitigating the adverse effects of poor social cognition on child adjustment (Hughes \& Lecce, 2010). Indeed, one potential target for intervention and social policy may be to support mothers who are less responsive to their infants in order to help them build the social cognitive skills that are essential for children's psychosocial health. 


\section{References}

Acock, A. C. (2005). Working with missing values. Journal of Marriage and Family, 67(4), 1012-1028.

Amato, P. R. (2001). Children of Divorce in the 1990s: An Update of the Amato and Keith (1991) meta-analysis. Journal of Family Psychology, 15, 355-370.

Ambady, N., Bernieri, F. J., \& Richeson, J. A. (2000). Toward a histology of social behavior: Judgmental accuracy from thin slices of the behavioral stream. Advances in experimental social psychology, 32, 201-271.

Ambady, N., \& Rosenthal, R. (1992). Thin slices of expressive behavior as predictors of interpersonal consequences: A meta-analysis. Psychological bulletin, 111(2), 256.

Aschersleben, G., Hofer, T., \& Jovanovic, B. (2008). The link between infant attention to goaldirected action and later theory of mind abilities. Developmental Science, 11(6), 862-868.

Astington, J. W. (2003). False-Belief Understanding and Social Competence. Individual differences in theory of mind: Implications for typical and atypical development, 14.

Astington, J. W. (2006). The developmental interdependence of theory of mind and language. Roots of human sociality, 179-206.

Astington, J. W., \& Baird, J. A. (2005). Why language matters for theory of mind: Oxford University Press, USA.

Astington, J. W., \& Jenkins, J. M. (1999). A longitudinal study of the relation between language and theory of mind development. Developmental Psychology, 35, 1311-1320.

Ayoub, C., O'Connor, E., Rappolt-Schlictmann, G., Vallotton, C., Raikes, H., \& Chazan-Cohen, R. (2009). Cognitive skill performance among young children living in poverty: Risk, change, and the promotive effects of Early Head Start. Early Childhood Research Quarterly, 24(3), 289-305.

Bailey, H. N., DeOliveira, C. A., Wolfe, V. V., Evans, E. M., \& Hartwick, C. (2012). The impact of childhood maltreatment history on parenting: A comparison of maltreatment types and assessment methods. Child Abuse \& Neglect.

Baillargeon, R., Scott, R. M., \& He, Z. (2010). False-belief understanding in infants. Trends in Cognitive Sciences, 14(3), 110-118.

Baldwin, D. A., \& Moses, L. J. (1994). Early understanding of referential intent and attentional focus: Evidence from language and emotion. Children's early understanding of mind: Origins and development, 133-156.

Banyard, V. L. (1997). The impact of childhood sexual abuse and family functioning on four dimensions of women's later parenting. Child Abuse \& Neglect, 21(11), 1095-1107. 
Baron-Cohen, S. (1989). The autistic child's theory of mind: A case of specific developmental delay. Journal of Child Psychology and Psychiatry, 30(2), 285-297.

Baron-Cohen, S. (1997). How to build a baby that can read minds: Cognitive mechanisms in mindreading. The maladapted mind, 207-239.

Baron-Cohen, S., Leslie, A. M., \& Frith, U. (1985). Does the autistic child have a theory of mind? Cognition, 21, 37-46.

Barresi, J., \& Moore, C. (1996). Intentional relations and social understanding. Behavioral and brain sciences, 19(01), 107-122.

Benson, J., \& Fleishman, J. A. (1994). The robustness of maximum likelihood and distributionfree estimators to non-normality in confirmatory factor analysis. Quality \& quantity, 28(2), 117-136.

Bernier, A., Carlson, S. M., \& Whipple, N. (2010). From External Regulation to Self-Regulation: Early Parenting Precursors of Young Children's Executive Functioning. Child Development, 81(1), 326-339.

Bowlby, J. (1982). Attachment and loss: Retrospect and prospect. American Journal of Orthopsychiatry, 52(4), 664-678.

Bradley, R. H., \& Caldwell, B. M. (1981). Home environment and infant social behaviour. Infant Mental Health Journal, 2, 18-22.

Bradley, R. H., \& Corwyn, R. F. (2002). Socioeconomic Status and Child Development. Annu. Rev. Psychol., 235-309.

Brody, G. H., \& Flor, D. L. (1998). Maternal resources, parenting practices, and child competence in rural, single-parent African American families. Child Development, 69(3), 803-816.

Bronfenbrenner, U. (1979). The ecology of human development: Experiments by nature and design: Harvard Univ Pr.

Bronfenbrenner, U., \& Morris, P. A. (2006). The bioecological model of human development. Handbook of child psychology.

Brown, T. A. (2006). Confirmatory factor analysis for applied research: The Guilford Press.

Brownell, C. A., \& Carriger, M. S. (1990). Changes in Cooperation and Self-Other Differentiation during the Second Year. Child Development, 61(4), 1164-1174.

Brownell, C. A., Zerwas, S., \& Ramani, G. B. (2007). "So Big": The Development of Body SelfAwareness in Toddlers. Child Development, 78(5), 1426-1440.

Burchinal, M., Vernon-Feagans, L., Cox, M., \& Investigators, K. F. L. P. (2008). Cumulative social risk, parenting, and infant development in rural low-income communities. Parenting: Science and Practice, 8(1), 41-69. 
Burchinal, M. R., Roberts, J. E., Zeisel, S. A., \& Rowley, S. J. (2008). Social risk and protective factors for African American children's academic achievement and adjustment during the transition to middle school. Developmental psychology, 44(1), 286.

Cabrera, N. J., Fagan, J., Wight, V., \& Schadler, C. (2011). Influence of Mother, Father, and Child Risk on Parenting and Children's Cognitive and Social Behaviors. Child Development.

Carpenter, M., Akhtar, N., \& Tomasello, M. (1998). Fourteen-through 18-month-old infants differentially imitate intentional and accidental actions. Infant Behavior and Development, 21(2), 315-330.

Carpenter, M., Call, J., \& Tomasello, M. (2005). Twelve- and 18-month olds copy actions in terms of goals. Developmental Science, 8(1), F13-F20.

Carpenter, M., Nagell, K., \& Tomasello, M. (1998). Social cognition, joint attention, and communicative competence from 9 to 15 months of age. Monographs of the Society for Research in Child Development., 63 (4).

Charman, T., Baron-Cohen, S., Swettenham, J., Baird, G., Cox, A., \& Drew, A. (2000). Testing joint attention, imitation, and play as infancy precursors to language and theory of mind. Cognitive Development, 15(4), 481-498.

Coldwell, J., Pike, A., \& Dunn, J. (2006). Household chaos-links with parenting and child behaviour. Journal of Child Psychology and Psychiatry, 47(11), 1116-1122.

Cole, D. A., \& Maxwell, S. E. (2003). Testing mediational models with longitudinal data: questions and tips in the use of structural equation modeling. Journal of Abnormal Psychology, 112(4), 558.

Csibra, G., Gergely, G., Biro, S., Koos, O., \& Brockbank, M. (1999). Goal attribution without agency cues: the perception of [] pure reason'in infancy. Cognition, 72(3), 237-267.

Cutting, A. L., \& Dunn, J. (1999). Theory of mind, emotion understanding, language and family background: Individual differences and interrelations. Child Development, 70, 853-865.

Dale, P. S. (1991). The validity of a parent report measure of vocabulary and syntax at 24 months. Journal of speech and hearing research, 34(3), 565.

Dale, P. S., Bates, E., Reznick, J. S., \& Morisset, C. (1989). The validity of a parent report instrument of child language at twenty months. Journal of child language, 16(2), 239-249.

Deater-Deckard, K., Pylas, M., \& Petrill, S. (1997). The Parent-child interaction system (PARCHISY). London: Institute of Psychiatry.

Dong, M., Anda, R. F., Felitti, V. J., Dube, S. R., Williamson, D. F., Thompson, T. J., et al. (2004). The interrelatedness of multiple forms of childhood abuse, neglect, and household dysfunction. Child Abuse \& Neglect, 28(7), 771-784. 
Dumas, J. E., Nissley, J., Nordstrom, A., Smith, E. P., Prinz, R. J., \& Levine, D. W. (2005). Home chaos: Sociodemographic, parenting, interactional, and child correlates. Journal of Clinical Child and Adolescent Psychology, 34(1), 93-104.

Dunn, J., \& Cutting, A. L. (1999). Understanding others, and individual differences in friendship interactions in young children. Social Development, 8(2), 201-219.

Enders, C. K., \& Bandalos, D. L. (2001). The relative performance of full information maximum likelihood estimation for missing data in structural equation models. Structural Equation Modeling, 8(3), 430-457.

Ereky-Stevens, K. (2008). Associations between mothers' sensitivity to their infants' internal states and children's later understanding of mind and emotion. Infant and Child Development, 17(5), 527-543.

Fenson, L., Dale, P. S., Reznick, J. S., Bates, E., Thal, D. J., Pethick, S. J., et al. (1994). Variability in early communicative development. Monographs of the society for research in child development.

Fernyhough, C. (2008). Getting Vygotskian about theory of mind: Mediation, dialogue, and the development of social understanding. Developmental Review, 28(2), 225-262.

Flouri, E., \& Kallis, C. (2007). Adverse life events and psychopathology and prosocial behavior in late adolescence: testing the timing, specificity, accumulation, gradient, and moderation of contextual risk. Journal American Academy Child and Adolescent Psychiatry, 46, 16511659.

Fonagy, P., Steele, M., Steele, H., Moran, G. S., \& Higgitt, A. C. (1991). The capacity for understanding mental states: The reflective self in parent and child and its significance for security of attachment. Infant mental health journal, 12(3), 201-218.

Gaffan, E. A., Martins, C., Healy, S., \& Murray, L. (2010). Early social experience and individual differences in infants' joint attention. Social Development, 19(2), 369-393.

Gallagher, H. L., \& Frith, C. D. (2003). Functional imaging of [] theory of mind'. Trends in Cognitive Sciences, 7(2), 77-83.

Garfield, J. L., Peterson, C. C., \& Perry, T. (2001). Social cognition, language acquisition and the development of the theory of mind. Mind \& Language, 16(5), 494-541.

Gergely, G., Nádasdy, Z., Csibra, G., \& Bíró, S. (1995). Taking the intentional stance at 12 months of age. Cognition, 56(2), 165-193.

Hale, C. M., \& Tager-Flusberg, H. (2003). The influence of language on theory of mind: A training study. Developmental Science, 6(3), 346-359.

Heilmann, J., Weismer, S. E., Evans, J., \& Hollar, C. (2005). Utility of the MacArthur--Bates Communicative Development Inventory in Identifying Language Abilities of Late-Talking 
and Typically Developing Toddlers. American Journal of Speech-Language Pathology, 14(1), 40.

Hu, L., \& Bentler, P. M. (1999). Cutoff criteria for fit indexes in covariance structure analysis: Conventional criteria versus new alternatives. Structural Equation Modeling: A Multidisciplinary Journal, 6(1), 1-55.

Hughes, C., Deater-Deckard, K., \& Cutting, A. L. (1999). 'Speak roughly to your little boy'? Sex Differences in the Relations Between Parenting and Preschoolers' Understanding of Mind. Social Development, 8(2), 143-160.

Hughes, C., \& Ensor, R. (2006). Behavioural problems in 2 year olds: links with individual differences in theory of mind, executive function and harsh parenting. Journal of Child Psychology and Psychiatry, 47(5), 488-497.

Hughes, C., Jaffee, S. R., Happe, F., Taylor, A., Caspi, A., \& Moffitt, T. E. (2005). Origins of individual differences in theory of mind: From nature to nurture? Child Development, 76(2), 356-370.

Hughes, C., \& Lecce, S. (2010). Early Social Cognition. Encyclopedia on Early Childhood Development, 1-6.

Ispa, J. M., Fine, M. A., Halgunseth, L. C., Harper, S., Robinson, J. A., Boyce, L., et al. (2004). Maternal Intrusiveness, Maternal Warmth, and Motherâe"Toddler Relationship Outcomes: Variations Across Lowâ€ Income Ethnic and Acculturation Groups. Child Development, 75(6), 1613-1631.

Jenkins, J. M., \& Astington, J. W. (1996). Cognitive factors and family structure associated with theory of mind development in young children. Developmental Psychology, 32, 70-78.

Keller, H., Kärtner, J., Borke, J., Yovsi, R., \& Kleis, A. (2005). Parenting styles and the development of the categorical self: A longitudinal study on mirror self-recognition in Cameroonian Nso and German families. International Journal of Behavioral Development, 29(6), 496-504.

Kiang, L., Moreno, A. J., \& Robinson, J. A. L. (2004). Maternal preconceptions about parenting predict child temperament, maternal sensitivity, and children's empathy. Developmental psychology, 40(6), 1081.

Kircher, T. T. J., Senior, C., Phillips, M. L., Rabe-Hesketh, S., Benson, P. J., Bullmore, E. T., et al. (2001). Recognizing one's own face. Cognition, 78(1), B1-B15.

Kochanska, G., DeVet, K., Goldman, M., Murray, K., \& Putnam, S. P. (1994). Maternal reports of conscience development and temperament in young children. Child Development, 65(3), 852-868.

Kochanska, G., Forman, D. R., Aksan, N., \& Dunbar, S. B. (2005). Pathways to conscience: Early motherâ€"child mutually responsive orientation and children's moral emotion, conduct, and cognition. Journal of Child Psychology and Psychiatry, 46(1), 19-34. 
Laranjo, J., Bernier, A., Meins, E., \& Carlson, S. M. (2010). Early Manifestations of Children's Theory of Mind: The Roles of Maternal Mind-Mindedness and Infant Security of Attachment. Infancy, 15(3), 300-323.

Lengua, L. J., Honorado, E., \& Bush, N. R. (2007). Contextual risk and parenting as predictors of effortful control and social competence in preschool children. Journal of Applied Developmental Psychology, 28(1), 40-55.

Leslie, A. M. (1994). Pretending and believing: Issues in the theory of ToMM. Cognition, 50(13), 211-238.

Lewis, M., Sullivan, M. W., Stanger, C., \& Weiss, M. (1989). Self Development and selfconscious emotions. Child Development, 60, 146-156.

Lovejoy, M. C., Graczyk, P. A., O'Hare, E., \& Neuman, G. (2000). Maternal depression and parenting behavior* 1:: A meta-analytic review. Clinical psychology review, 20(5), 561592.

Lucariello, J. M., Durand, T. M., \& Yarnell, L. (2007). Social versus intrapersonal ToM: Social ToM is a cognitive strength for low-and middle-SES children. Journal of Applied Developmental Psychology, 28(4), 285-297.

MacKinnon, D. P., Fairchild, A. J., \& Fritz, M. S. (2007). Mediation analysis. Annual review of psychology, 58, 593.

MacKinnon, D. P., Lockwood, C. M., Hoffman, J. M., West, S. G., \& Sheets, V. (2002). A comparison of methods to test mediation and other intervening variable effects. Psychological methods, 7(1), 83.

Martinez Jr, C. R., \& Forgatch, M. S. (2002). Adjusting to change: Linking family structure transitions with parenting and boys' adjustment. Journal of Family Psychology, 16(2), 107.

Matias, C., Scott, S., \& O’Connor, T. G. (2006). Coding of Attachment-Related Parenting (CARP).

McCabe, K., Houser, D., Ryan, L., Smith, V., \& Trouard, T. (2001). A functional imaging study of cooperation in two-person reciprocal exchange. Proceedings of the National Academy of Sciences, 98(20), 11832.

Meins, E., Fernyhough, C., Russell, J., \& Clark-Carter, D. (1998). Security of attachment as a predictor of symbolic and mentalising abilities: A longitudinal study. Social Development, $7(1), 1-24$.

Meins, E., Fernyhough, C., Wainwright, R., Das Gupta, M., Fradley, E., \& Tuckey, M. (2002). Maternal mind-mindedness and attachment security as predictors of theory of mind understanding. Child Development, 73(6), 1715-1726.

Meltzoff, A. N. (1995). Understanding the intentions of others: Re-enactment of intended acts by 18-month-old children. Developmental psychology, 31(5), 838. 
Meltzoff, A. N., Gopnik, A., \& Repacholi, B. M. (1999). Toddlers' understanding of intentions, desires and emotions: Explorations of the dark ages.

Meunier, J. C., Jenkins, J. M., Boyle, M. H., \& O’Connor, T. G. (2011). Multilevel mediation: Contextual risks, maternal differential treatment and children's behaviour within families. Revise and resubmit: Child Development.

Moore, C. (2007). Understanding self and others in the second year. Socioemotional development in the toddler years: Transitions and transformations, 43-65.

Morales, M., Mundy, P., Delgado, C. E. F., Yale, M., Messinger, D., Neal, R., et al. (2000). Responding to joint attention across the 6-through 24-month age period and early language acquisition. Journal of Applied Developmental Psychology, 21(3), 283-298.

Mumme, D. L., Fernald, A., \& Herrera, C. (1996). Infants' responses to facial and vocal emotional signals in a social referencing paradigm. Child Development, 67(6), 3219-3237.

Mundy, P., Delgado, C., Block, J., Venezia, M., Hogan, A., \& Seibert, J. (2003). Early Social Communikation Scales (ESCS). Coral Gables, FL: University of Miami.

Muthén, B., \& Muthén, L. (2010). Mplus (Version 6). Los Angeles, CA: Author.

Nelson, K. (2005). Language pathways into the community of minds. Why language matters for theory of mind, 26-49.

NICHD (1999). Chronicity of Maternal Depressive Symptoms, Maternal Sensitivity, and Child Functioning at 36 Months. Developmental Psychology, 35(5), 1297-1310.

Nielsen, M., \& Dissanayake, C. (2004). Pretend play, mirror self-recognition and imitation: A longitudinal investigation through the second year. Infant Behavior and Development, 27(3), 342-365.

Prime, H., Perlman, M., Tackett, J., \& Jenkins, J. M. (2011). The development and validation of a thin-slice approach for coding scaffolding between siblings. In preparation.

Radloff, L. S. (1977). The CES-D scale: A self-report depression scale for research in the general population. Applied Psychological Measurement, 1, 385-401.

Raviv, T., Kessenich, M., \& Morrison, F. J. (2004). A mediational model of the association between socioeconomic status and three-year-old language abilities: The role of parenting factors. Early Childhood Research Quarterly, 19(4), 528-547.

Raykov, T., \& Marcoulides, G. A. (2004). Using the delta method for approximate interval estimation of parameter functions in SEM. Structural Equation Modeling, 11(4), 621-637.

Reddy, V. (2008). How infants know minds: Harvard Univ Pr.

Rohrer, L. M., Cicchetti, D., Rogosch, F. A., Toth, S. L., \& Maughan, A. (2011). Effects of maternal negativity and of early and recent recurrent depressive disorder on children's false belief understanding. Developmental psychology, 47(1), 170. 
Ruffman, T., Slade, L., Devitt, K., \& Crowe, E. (2006). What mothers say and what they do: The relation between parenting, theory of mind, language and conflict/cooperation. British Journal of Developmental Psychology, 24(1), 105-124.

Rutter, M. (1979). Protective factors in children's responses to stress and disadvantage. In M. W. Kent \& J. E. Rolf (Eds.), Primary prevention in psychopathology, Vol. 3: Social competence in children (pp. 49-74). Hanover, NH: University Press of New England.

Sameroff, A. (2000). Ecological perspectives on developmental risk. WAIMH handbook of infant mental health, 4, 1-33.

San Juan, V., \& Astington, J. W. (2012). Bridging the gap between implicit and explicit understanding: How language development promotes the processing and representation of false belief. British Journal of Developmental Psychology, 30(1), 105-122.

Siegal, M., \& Varley, R. (2002). Neural systems involved in 'theory of mind'. Nature Reviews Neuroscience, 3(6), 463-471.

Silvern, L. (1994). Parenting and family stress as mediators of the long-term effects of child abuse. Child Abuse \& Neglect, 18(5), 439-453.

Slaughter, V., Dennis, M. J., \& Pritchard, M. (2002). Theory of mind and peer acceptance in preschool children. British Journal of Developmental Psychology, 20(4), 545-564.

Sobel, M. E. (1982). Asymptotic confidence intervals for indirect effects in structural equation models. Sociological methodology, 13(1982), 290-312.

Spreng, R. N., Mar, R. A., \& Kim, A. S. N. (2009). The common neural basis of autobiographical memory, prospection, navigation, theory of mind, and the default mode: a quantitative meta-analysis. Journal of cognitive neuroscience, 21(3), 489-510.

Stone, V. E., Baron-Cohen, S., \& Knight, R. T. (1998). Frontal lobe contributions to theory of mind. Journal of cognitive neuroscience, 10(5), 640-656.

Symons, D. K., \& Clark, S. E. (2000). A Longitudinal Study of Motherâ€ Child Relationships and Theory of Mind in the Preschool Period. Social Development, 9(1), 3-23.

Taumoepeau, M., \& Ruffman, T. (2006). Mother and infant talk about mental states relates to desire language and emotion understanding. Child Development, 77(2), 465-481.

Thal, D. J., O'Hanlon, L., Clemmons, M., \& Fralin, L. S. (1999). Validity of a parent report measure of vocabulary and syntax for preschool children with language impairment. Journal of Speech, Language, and Hearing Research, 42(2), 482.

Thoermer, C., Sodian, B., Vuori, M., Perst, H., \& Kristen, S. (2012). Continuity from an implicit to an explicit understanding of false belief from infancy to preschool age. British Journal of Developmental Psychology, 30(1), 172-187.

Tomasello, M., \& Carpenter, M. (2007). Shared intentionality. Developmental Science, 10(1), 121-125. 
Tomasello, M., Carpenter, M., Call, J., Behne, T., \& Moll, H. (2005). Understanding and sharing intentions: The origins of cultural cognition. Behavioral and brain sciences, 28(5), 675690.

Trentacosta, C. J., Hyde, L. W., Shaw, D. S., Dishion, T. J., Gardner, F., \& Wilson, M. (2008). The relations among cumulative risk, parenting, and behavior problems during early childhood. Journal of Child Psychology and Psychiatry, 49(11), 1211-1219.

Vogeley, K., Bussfeld, P., Newen, A., Herrmann, S., Happe, F., Falkai, P., et al. (2001). Mind reading: neural mechanisms of theory of mind and self-perspective. Neuroimage, 14(1), $170-181$.

Vollm, B. A., Taylor, A. N. W., Richardson, P., Corcoran, R., Stirling, J., McKie, S., et al. (2006). Neuronal correlates of theory of mind and empathy: a functional magnetic resonance imaging study in a nonverbal task. Neuroimage, 29(1), 90-98.

Vygotsky, L. S. (1997). The Collected Works of LS Vygotsky: Problems of the Theory and History of Psychology Including the Chapter on the Crisis in Psychology (Vol. 3): Springer.

Walsh, C. A., MacMillan, H. L., Trocme, N., Jamieson, E., \& Boyle, M. H. (2008). Measurement of victimization in adolescence: Development and validation of the Childhood Experiences of Violence Questionnaire. Child Abuse \& Neglect, 32(11), 1037-1057.

Walter, H., Adenzato, M., Ciaramidaro, A., Enrici, I., Pia, L., \& Bara, B. G. (2004). Understanding intentions in social interaction: The role of the anterior paracingulate cortex. Journal of cognitive neuroscience, 16(10), 1854-1863.

Warneken, F., Chen, F., \& Tomasello, M. (2006). Cooperative activities in young children and chimpanzees. Child Development, 77(3), 640-663.

Warneken, F., \& Tomasello, M. (2006). Altruistic helping in human infants and young chimpanzees. Science, 311(5765), 1301.

Wellman, H. M., Lopez-Duran, S., LaBounty, J., \& Hamilton, B. (2008). Infant attention to intentional action predicts preschool theory of mind. Developmental psychology, 44(2), 618.

Wellman, H. M., Phillips, A. T., Dunphy-Lelii, S., \& LaLonde, N. (2004). Infant social attention predicts preschool social cognition. Developmental Science, 7(3), 283-288.

West, S. G., Finch, J. F., \& Curran, P. J. (1995). Structural equation models with nonnormal variables: Problems and remedies.

Whipple, S. S., Evans, G. W., Barry, R. L., \& Maxwell, L. E. (2010). An ecological perspective on cumulative school and neighborhood risk factors related to achievement. Journal of Applied Developmental Psychology, 31(6), 422-427. 
Williams, J. H. G., Waiter, G. D., Perra, O., Perrett, D. I., \& Whiten, A. (2005). An fMRI study of joint attention experience. Neuroimage, 25(1), 133-140.

Woodward, A. L. (1998). Infants selectively encode the goal object of an actor's reach. Cognition, 69(1), 1-34.

Zahn-Waxler, C., \& Radke-Yarrow, M. (1990). The origins of empathic concern. Motivation and Emotion, 14(2), 107-130.

Zahn-Waxler, C., Radke-Yarrow, M., Wagner, E., \& Chapman, M. (1992). Development of concern for others. Developmental psychology, 28(1), 126. 